\title{
The Rationale for a Different Approach to Preventing Cardiovascular Disease
}

\author{
David S. Schade ${ }^{*}$, Barry Ramo², S. Scott Obenshain ${ }^{3}$, Ron Schrader ${ }^{4}$, R. Philip Eaton ${ }^{1}$ \\ ${ }^{1}$ Division of Endocrinology, Department of Internal Medicine, University of New Mexico Health Sciences Center, Albuquerque, NM, \\ USA \\ ${ }^{2}$ New Heart Fitness and Health, Albuquerque, NM, USA \\ ${ }^{3}$ Department of Pediatrics, University of New Mexico Health Sciences Center, Albuquerque, NM, USA \\ ${ }^{4}$ Department of Mathematics, University of New Mexico, Albuquerque, NM, USA \\ Email: *dschade@salud.unm.edu, barryramo@newheartnm.com, obenshainscott3@gmail.com,rmsbiostats@gmail.com, \\ rpeaton@salud.unm.edu
}

How to cite this paper: Schade, D.S., Ramo, B., Obenshain, S.S., Schrader, R. and Eaton, R.P. (2019) The Rationale for a Different Approach to Preventing Cardiovascular Disease. World Journal of Cardiovascular Diseases, 9, 489-510. https://doi.org/10.4236/wjcd.2019.97043

Received: June 5, 2019

Accepted: July 28, 2019

Published: July 31, 2019

Copyright $\odot 2019$ by author(s) and Scientific Research Publishing Inc. This work is licensed under the Creative Commons Attribution International License (CC BY 4.0).

http://creativecommons.org/licenses/by/4.0/

\begin{abstract}
The Problem: We have previously suggested that an alternative approach to preventing cardiovascular disease is necessary because atherosclerotic cardiovascular disease (ASCVD) has been increasing for the last 50 years and has now reached epidemic status. Since the year 2000, approximately 600,000 heart attacks and ASCVD related deaths have occurred annually in the United States. It is the most common cause of death in the U.S., more than all cancers combined. The financial costs are staggering, amounting to 555 billion dollars per year in direct and indirect costs. Outlook for an improvement in these statistics is not encouraging as the U.S. population continues to become more obese and to develop diabetes. The Question: Why is ASCVD continuing to be a major challenge to healthcare providers when the pathogenesis is known and inexpensive preventative treatment is available? The reasons are multiple and complex. First, present financial reimbursement policies of healthcare organizations reward treatment of a disease and its complications instead of preventing the disease. Second, professional guidelines and treatment goals are often too complex, subject to interpretation, and time-consuming to be useful in the clinical setting. Third, no specific follow-up of patients at risk for ASCVD is recommended when the risk assessment changes. Fourth, many expensive cardiovascular diagnostic tests are utilized without meeting appropriate guidelines for their use. Fifth, treatment of individuals without first proving the presence of disease results in poor adherence to therapy. The Solution: This article describes the rationale for a new approach to the prevention of ASCVD in asymptomatic individuals. It is based upon preventing ASCVD by identifying all asymptomatic individuals
\end{abstract}


with subclinical disease before an ASCVD event occurs. It recommends that all adults be screened for ASCVD on or before the age of 50 using a non-invasive atherosclerosis specific coronary artery calcium heart scan. Further recommendations include treating all calcium positive individuals to reverse their atherosclerotic coronary artery plaques with a combination of a low cholesterol diet, rosuvastatin $10 \mathrm{mg} /$ day, and ezetimibe $10 \mathrm{mg} /$ day. The therapeutic goal is a low-density lipoprotein cholesterol below $50 \mathrm{mg} / \mathrm{dl}$ to ensure regression of atherosclerosis. For individuals who have a zero calcium score, a repeat scan in 3 to 5 years is recommended. This new approach can easily be integrated into ongoing heart disease prevention programs to reduce the burden of ASCVD within the next five years. Conclusion: The mortality, morbidity, and cost of ASCVD have reached unacceptable levels. Reducing this disease to a rare condition will require the efforts of many individuals to organize, educate, and facilitate the goal of identifying all individuals with subclinical ASCVD. Once identified, aggressive therapy is required to reverse their atherosclerotic plaques in order to prevent heart attacks and atherosclerotic strokes. If successful, within 5 years the majority of the patients with asymptomatic ASCVD can be identified and if treated appropriately, reduce the prevalence and cost of ASCVD by $90 \%$.

\section{Keywords}

Cardiovascular Disease, Preventing, ASCVD

\section{Background}

The statistics are staggering. Every minute at least one individual has a heart attack in the United States [1]. This equates to 600,000 persons per year, the size of a small city (Figure 1). This large number is more than all cancers combined. Furthermore, the prevalence of heart disease is increasing in spite of billions of dollars spent on treatment each year. The cost to society for each heart attack is $\$ 94,000$ (direct plus indirect costs) according to the American Heart Association [1]. The total cost in the United States of cardiovascular disease is 555 billion dollars per year and is projected to triple by 2039 [1]. Not included in these costs is the untold suffering and financial ruin experienced by innumerable families caring for heart attack victims. What is astounding is that cardiovascular disease is not a newly recognized disease entity, with an unknown cause and an unknown preventative treatment. In fact, its pathogenesis and effective prevention have been described in detail during the last 20 years, including the genetic determinants [2] [3] [4]. Half of acute coronary events occur in asymptomatic patients and nearly $70 \%$ of acute coronary events result from coronary lesions that are not obstructing flow prior to the event [5]. The purpose of this article is to begin the dialogue to change the current approach to cardiovascular disease to an alternative one that is effective, cost-saving, safe, and feasible. 


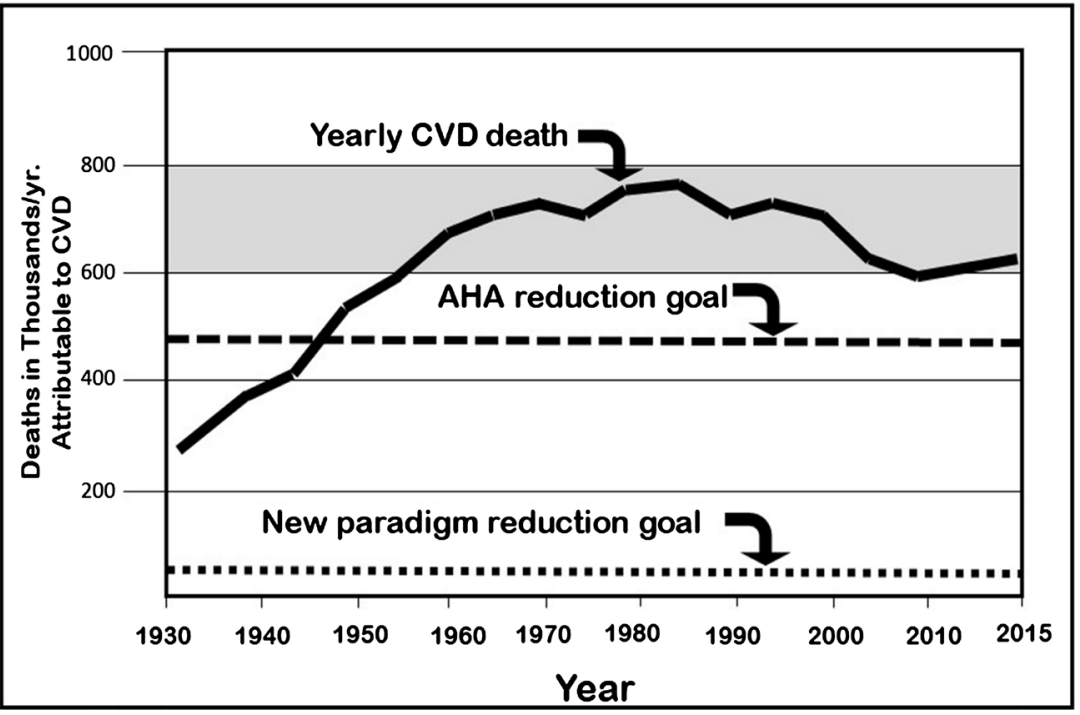

Figure 1. Deaths attributable to diseases of the heart (data from [1]). Between 1960 and 2015 , the death rate has remained between 600,000 and 800,000 individuals per year in the United States. The goals for reducing these deaths are $20 \%$ for the American Heart Association [8] and 90\% for the new proposed paradigm.

The popular press often cites statistics showing that the death rate from cardiovascular disease is declining, and attributes this reduction to a decline in risk factors for ASCVD, especially smoking. Although this may be partially true for some risk factors, it is being counterbalanced by the increase in other risk factors such as obesity, diabetes, and insulin resistance [6]. Of particular importance is the fact that the overall prevalence of cardiovascular disease is increasing [7]. The burden of cardiovascular disease is increasing at an alarming rate due to the obesity epidemic, poor diet, high blood pressure, the aging population, and a dramatic rise in Type 2 diabetes-all major risk factors for heart disease and stroke. In 2015, the death rate from heart disease actually increased by 1 percent for the first time since 1969 [8]. In addition, ASCVD has become our nation's costliest chronic disease. In 2014, stroke and heart failure were the most expensive chronic conditions in the Medicare fee-for-service program. In 2011 the American Heart Association (AHA) predicted that by 2030, upwards of 40 percent of the U.S. population (more than 100 million Americans) would suffer from some form of ASCVD. Amazingly, that benchmark was reached in 2015-almost 15 years sooner than predicted [8].

Unfortunately, ASCVD and its associated risk factors exact a disproportionate toll on many racial and ethnic groups, accounting for almost 40 percent of the disparity in life expectancy between blacks and whites. Stroke and heart failure top the list of chronic conditions that account for the most spending in the Medicare fee-for-service program. This spending pattern reflects how the U.S. health care system often rewards efforts that treat disease and injury rather than those that prevent them. Cardiovascular disease is largely preventable, and prevention programs represent an enormous return on investment by reducing 
some costs and promoting patient well-being, including length and quality of life [8].

\section{The Critical Question}

Why has this disease not been eliminated or at least reduced to a rare occurrence? The answer relates in part to the observation that, on average, it takes 17 years for medical advances to be applied to patient care [9]. The reasons for this delay are complex and not easily changed. When the public recognizes that an epidemic is a reality and demands a solution from the medical establishment, sufficient resources are then devoted to finding a rapid treatment or solution (e.g., the AIDS epidemic). In spite of the fact that many more individuals are dying of cardiovascular disease than AIDS, no public outcry about ASCVD has been forthcoming. People worry more about getting cancer than having a heart attack in spite of the fact that more individuals are likely to die of cardiovascular disease [8]. The stated 2018 goal of the AHA is to reduce cardiovascular disease by $20 \%$ [8]. Even in the unlikely event that this goal is achieved, it would still leave 480,000 individuals with heart attacks each year. Based on the AHA's own report, any reduction in cardiovascular disease is doubtful nor is a reduction in cardiovascular mortality likely [1]. For these reasons, a new paradigm for preventing cardiovascular disease is urgently needed.

\section{The Current Approach}

Before describing a new paradigm to prevent ASCVD, it may be useful to examine the limitations of the current medical approach to ASCVD.

1) Many asymptomatic individuals with no proven ASCVD are placed on preventive pharmacological therapy who would never experience cardiovascular disease in their lifetime [10].

This phenomenon is termed "overtreatment" and applies to several groups including smokers, patients with diabetes, and the elderly. Patients dislike being treated for a lifetime without knowing that the treatment is beneficial. The result is that compliance to preventative treatment is marginal. For example, only $50 \%$ of 75-year-old patients are still taking a prescribed statin six months after beginning "preventative" treatment [11]. Recent evidence suggests that patients do not want to take statin medications to prevent ASCVD, even if it would potentially add years to their lives [12] [13]. In addition, overtreatment exposes many individuals to unnecessary adverse effects and costs of the prescribed medications.

2) High doses of statins are often prescribed before alternative medications (such as ezetimibe) are employed [14].

This occurs in spite of the fact that the side effects of statins (myalgias and diabetes) are dose related and Robert's rule states that the doubling of a statin dose only increases its low density lipoprotein cholesterol (LDLc) lowering capacity by $7 \%$ [15]. One reason for this observation is the increase in proprotein convertase subtilsin-kexin type 9 (PCSK9) induced by statins that reduces their ef- 
fectiveness [16]. In contrast, ezetimibe reduces LDLc concentration $20 \%$ with similar side effects to placebo treatment [17]. When used with a high potency statin, the LDLc lowering effects are additive and the side effects are the same as using the statin alone [18].

3) The goals of statin therapy for most intermediate risk individuals is 70 $m g / d l$ in spite of extensive data demonstrating that the lower the LDLC cholesterol, the lower the ASCVD event rate [19].

Since reversal of atherosclerosis has been shown to occur at approximately 70 $\mathrm{mg} / \mathrm{dl}$ or below, many individuals will still be producing atherosclerotic plaques at $70 \mathrm{mg} / \mathrm{dl}$ (they are on the wrong side of the reversal, bell shaped curve.) [14]. Furthermore, LDLc levels significantly below $70 \mathrm{mg} / \mathrm{dl}$ have been shown to be safe and attainable [20].

4) The cost of health care has continued to increase during the last ten years.

A large part of this cost is due to ASCVD and the increasing array of invasive procedures, poly pharmacy, and hospitalizations necessary to maintain individuals suffering from an ASCVD event. The current expenditure for ASCVD care approximates $\$ 1,000$ year for every man, women, and child in the US. This cost is projected to triple by year 2035 [1]. These costs have a detrimental effect on the quality of medical care, which preferentially affect the poor and unemployed individuals.

5) Testing a patient for heart disease can be very expensive.

In addition to the cost of multiple physician visits, a myriad of testing procedures is available. For example, a stress test costs $\$ 500$ or more depending on whether pharmacological stimulation or radioactive isotopes are also employed. The main limitation of a stress test is that it does not identify the site of obstruction, even if one exists. It has been estimated that more than 56,000 unnecessary stress tests are done each year in the United States [21]. Coronary angiography costs between $\$ 5000$ and $\$ 10,000$ and frequently follows a stress test. This test is often done in spite of the limited information it provides [22] and the fact that it does not predict the arterial location of a future heart attack [23]. When a coronary artery constriction is identified on angiography, one or more stents may be placed in the artery to reduce perceived angina, in spite of a randomized controlled trial demonstrating that placing a stent in non-acutely ill patients is not superior to aggressive medical therapy except for limited pain relief [24]. The benefits of medical therapy in preference to coronary revascularization for suppression of ischemia have been demonstrated in stable patients after acute myocardial ischemia [25]. Furthermore, the total cost of stent placement approaches $\$ 40,000$.

6) The physician attempting to follow the most current recommendations for preventing ASCVD faces a bewildering task.

There are at least 21 professional organizations that publish recommendations for treating ASCVD [26]. Not surprisingly, there is little agreement among or- 
ganizations' recommendations [26]. In addition, most recommendations are too complex to be useful to caregivers trying to take care of individual patients [27]. This is one of several reasons that physicians do not follow clinical practice guidelines [28]. Organizations tend to rely on results of randomized controlled trials in spite of the fact that most of these trials have poor external validity (i.e., application to patients seen in the clinic) [29]. In addition, the major organizations have not increased the number of randomized clinical trials since 2004 upon which their recommendations are based [30]. This complexity and poor applicability are frequently recognized and result in short abbreviated synopses in medical journals [31]. Whether these summaries are actually useful to practicing physicians is unknown.

7) A major deficiency in current recommendations to prevent cardiovascular disease is the lack of planned follow-up.

For example, what should the physician do if the patient improves his lifestyle (by getting adequate exercise, achieving normal body weight, and following a low cholesterol diet) or alternatively, gains significant weight and develops prediabetes? Even if the patient does not change his lifestyle, his risk for cardiovascular disease will increase as he ages, since advancing age is the most significant risk factor for ASCVD [32] [33]. Furthermore, the degree of risk is often different when a ten year risk assessment is compared to a 30 year assessment [34]. No guidance is provided to the practitioner by current recommendations on how often or how he should reassess his patient or change his therapeutic approach.

8) The use of the global risk calculator misclassifies the degree of risk in many individuals [35].

Current guidelines suggest using one of the several available internet risk score calculators to assess risk of an individual patient [27]. By their very nature, these risk scores do not include several ASCVD risk factors because of their complexity, lack of availability, and inability to be measured accurately (e.g., genetic predisposition to ASCVD or protection from ASCVD, which can only be measured indirectly from family history). They also do not quantitate well individuals who have changed their risk categories such as gaining weight, stopping and starting smoking, developing diabetes, etc. Since these risk scores may be used to decide whether to treat patients with medications, both under treatment and over treatment of ASCVD is inevitable. However, combining risk scores with coronary artery calcium (CAC) scores provides an improved risk prediction [36].

Because of these multiple problems with current ASCVD recommendations, a new approach is warranted. These new recommendations should meet the following criteria:

1) Only treat individuals with proven cardiovascular disease.

Since ASCVD is not a contagious disease, accomplishing herd immunity by treating all patients at some prespecified level of risk affords no protection to unaffected individuals. Therefore, the current recommendations of prescribing pharmacological therapy to individuals who have no proven coronary atheros- 
clerosis and who would never get ASCVD, only expose them to the medication's cost and adverse effects [37]. In contrast, the proposed approach of treating only individuals with proven cardiac lesions focuses treatment that patients and caregivers can understand as preventing future catastrophic cardiovascular events. A positive coronary artery calcium CAC score provides a strong incentive for adherence to therapy and results in a significant reduction in both medication compliance and ASCVD risk factors [38].

2) When asymptomatic ASCVD is diagnosed, treat aggressively with inexpensive and minimal side effect medications.

The goal of therapy should be to reverse and eliminate ASCVD, not just to reduce the non-specific risk calculation to a lower level. An LDLc goal of $<50$ $\mathrm{mg} / \mathrm{dl}$ is achievable in almost all individuals who do not have a severe genetic defect in apolipoprotein B or the LDLc hepatic receptor. An LDLc goal of $<50$ $\mathrm{mg} / \mathrm{dl}$ is safe (normally present at birth) and below the average LDLc of 70 $\mathrm{mg} / \mathrm{dl}$, the level at which atherosclerotic plaques start to be reversed in patients with proven disease [39].

\section{3) A low cholesterol diet is preferable to a weight loss diet.}

Although achieving normal body weight and exercise is healthful [40], it should not necessarily be the goal of ASCVD preventive therapy. Instead, the recommendation should emphasize "eating smart," which involves avoiding foods that increases circulating LDLc (such as egg yolks and saturated fats] [41] [42]. Eating smart is readily achievable because it does not require weight loss or excluding desirable foods. It involves eating and preparing specific foods in moderation and with foresight to reduce LDLc.

4) Diagnosing ASCVD should be done non-invasively and at a very modest cost.

The coronary artery calcium scan meets both of these requirements. It not only establishes the presence of coronary plaques and predicts future risk better than currently employed cardiovascular testing methods [43], but it also provides an assessment of overall atherosclerotic burden [44]. At autopsy, increasing coronary calcium areas are associated with increasing advanced atherosclerotic lesions, regardless of patient gender [45]. The prevalence of a positive CAC score at different ages has been described (Figure 2) [46]. The CAC score is not a perfect test. It does not identify non-calcified plaques that can erupt and cause a coronary occlusion. For this reason, it is not as sensitive or as specific as intracoronary ultrasound or coronary angiography [47]. However, both of these tests are invasive, expensive and not amenable to general use in asymptomatic individuals. Of importance is the observation that Individuals with a zero calcium score have a minimum number of non-calcified plaques [48]. For this reason, the prognosis of individuals with a zero CAC score is excellent. For example, in the Multi-ethnic Study of Atherosclerosis (MESA) database of 6,698 adults followed for seven years, individuals with no major risk factors had a CHD event rate of only 2.1 per 1,000 years [35]. Even with risk factors, the CAC score of 


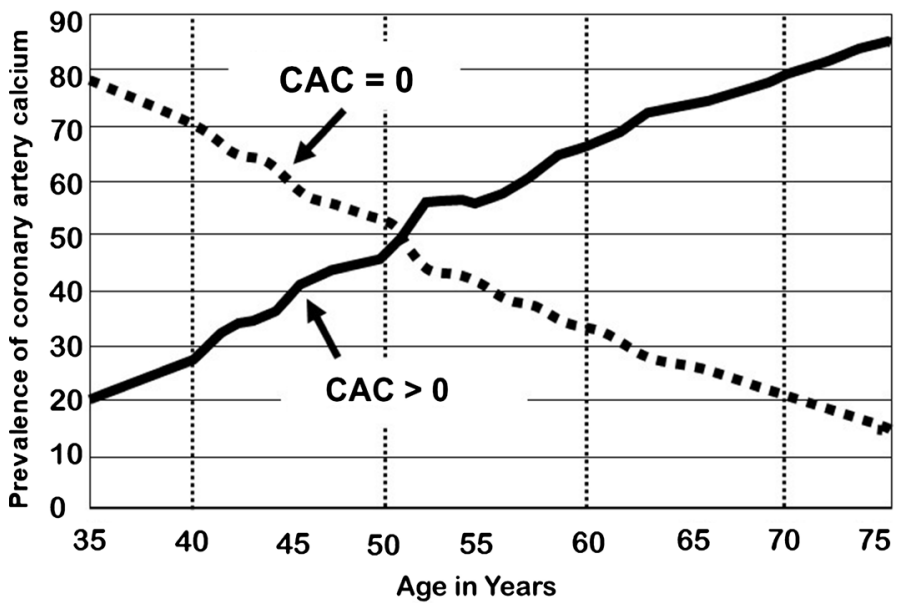

Figure 2. Changes in the prevalence of coronary artery calcium (CAC) with increasing age in 44,052 asymptomatic individuals referred for risk stratification. At 40 years of age, $\sim 30 \%$ of adults have a positive score; at 50 years $\sim 50 \%$ are positive; at 60 years $\sim 65 \%$ are positive; and at 70 years $\sim 80 \%$ are positive. If all adults are screened with a CAC study by age 50, approximately half of them will have subclinical ASCVD. (Data derived from [46]).

zero was predictive of lower risk [49]. This is true even in Type 2 diabetes, at least in the short term [50] [51]. In the largest meta-analysis published including 29,312 asymptomatic individuals, a zero CAC scan resulted in only 154 ASCVD events $(0.43 \%)$ during an observation period of 4.3 years [52]. In contrast, individuals with even a low score $(<10)$ are at increased risk for an ASCVD event compared to individuals with a zero score [53]. Since atherosclerosis is a progressive disease and CAC scores almost always progress [54], all individuals with a positive CAC score should be treated. The only exception to this recommendation is individuals with a score between one and ten. There is a small variability between different types of scanners and even between the initial and a repeat CAC score in an individual [55]. Therefore, the recommendation for treatment of an individual with a score of 1 to 10 should be left to a discussion between the primary care physician and the patient. If the decision is not to treat, then the CAC score should be repeated within 5 years.

The CAC test has been criticized by the United States Public Service Task Force because there are no randomized clinical trials demonstrating that its use results in a reduction of ASCVD events [56]. However, the problem with this conclusion is that it presupposes that a "test" by itself should result in a favorable outcome. It has been estimated that to do a randomized clinical outcomes trial comparing CAC testing with no testing would require between 50,000 and 100,000 participants and at least ten years of observation [5]. This study is not only impractical, but probably not feasible as new anti-atherosclerotic therapies may become available during the clinical trial. It is more reasonable to base the merits of the CAC test on its ability to detect ASCVD and to predict future ASCVD events. There are several excellent reviews available describing the strengths and weaknesses of CAC testing [57] [58] [59].

5) In patients with no identifiable ASCVD, periodic reassessment is crit- 
ical to identifying individuals who later develop asymptomatic ASCVD.

Similar to other preventative testing (e.g., mammography for breast cancer and colonoscopy for colon cancer), repeat coronary artery calcium scanning should be repeated at specified intervals. A reasonable interval is every four years for individuals with any significant risk factors and every five years for individuals with no risk factors. Yearly serial CAC scanning has demonstrated that in individuals with an initial zero CAC score, follow-up at 4 years results in $12 \%$ of individuals becoming CAC positive and $25 \%$ at five years [60]. Use of one of the several total risk scores may be useful in identifying asymptomatic individuals at particularly high risk for ASCVD [36].

6) Treatment algorithms must be simple and effective.

Defining goals of therapy is important to both caregivers and patients. Meeting the criteria of an LDLc of $<50 \mathrm{mg} / \mathrm{dl}$ for all individuals with proven ASCVD is simple, safe, and effective. The preferred treatment approach is to use a low dose of rosuvastatin $(10 \mathrm{mg})$ plus ezetimibe $(10 \mathrm{mg})$; the latter will lower the LDLC an additional 20\% [61]. In concert with a low cholesterol diet, this combination will reduce almost all individuals with an initial $\mathrm{LDLc}<150 \mathrm{mg} / \mathrm{dl}$ to an LDLC $<50 \mathrm{mg} / \mathrm{dl}$ at a cost of approximately 60 cents/day [62]. Many medical insurance companies now provide these medications at minimal or no charge.

7) The new paradigm must be capable of being integrated with the current approach to ASCVD prevention.

It is important to continue the current efforts at improving lifestyle and treating proven ASCVD with modern technics, medications, and procedures. Moreover, as the new paradigm is gradually incorporated into a community, the incidence of new onset ASCVD will decrease substantially. At this point, the major expenses of providing ongoing cardiac care will decrease. At some point, the usefulness of coronary artery stents, coronary bypass procedures, and cardiac assist devices will be minimal.

\section{A Simplified Approach-The Goal of Prevention Is to Identify Subclinical ASCVD in All Adults before an ASCVD Event Occurs}

This approach requires testing asymptomatic individuals for heart disease before they have a heart attack or stroke [63] (Figure 3). In reality, this dictates testing everyone by the age of 50 years and individuals after the age of 40 who are at intermediate risk or greater. Figure 2 demonstrates that a significant number of individuals at these ages will have a positive calcium score. Once a positive CAC scan is identified, the goal of therapy is an LDLc $<50 \mathrm{mg} / \mathrm{dl}$ [64]. This is readily achieved with a low cholesterol diet, rosuvastatin $10 \mathrm{mg} /$ day and ezetimibe 10 $\mathrm{mg} / \mathrm{d}$. At these low medication dosages, adverse effects are minimal and the benefits of reducing ASCVD are great. For individuals with zero score CAC scans, a repeat CAC scan in five years is recommended and earlier at four years if major risk factors are present [60]. 


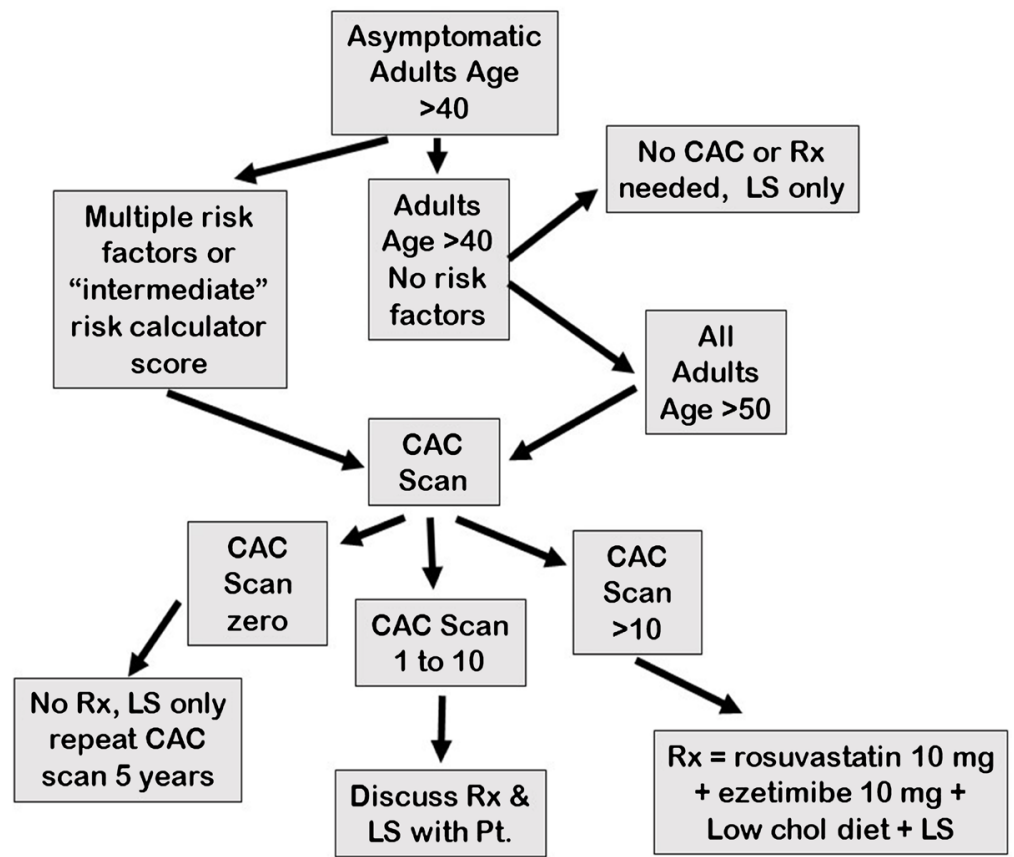

Figure 3. A stepwise algorithm to identify adults who need therapy to reverse their ASCVD. By age 50, all adults should have been screened for ASCVD or be on ASCVD reversal therapy. If the initial coronary artery calcium (CAC) score is zero, a repeat CAC scan should be done within 5 years. Only individuals with proven ASCVD receive therapy. $\mathrm{LS}=$ lifestyle improvement; $\mathrm{Rx}=$ Treatment; $\mathrm{Pt}=$ Patient.

\section{1) Why the recommendation of a $<50 \mathrm{mg} / \mathrm{dl}$ goal for $L D L c$ ?}

All studies that have examined the relationship between LDLc and ASCVD events have demonstrated that the lower the LDLc, the fewer the ASCVD events [65]. However, there are very little long-term data demonstrating that very low LDLc is safe (i.e., $<30 \mathrm{mg} / \mathrm{dl}$ ). To date, the only time that circulating LDLc has been shown to be necessary for hormonal synthesis is in the fetus, whose adrenal gland utilizes it for steroidogenesis [66] [67]. This occurs because at that time other hormone producing glands, especially the placenta, are not mature enough to synthesize sufficient cholesterol for hormonal requirements. The long-term data that very low levels of circulating LDLc are safe comes from patients with genetically induced hypobetalipoproteinemia. In these individuals with approximately $25 \%$ of circulating apoB lipoprotein, no hormonal abnormalities have been reported [68]. Short-term data (three years or less) that low levels of LDLc are safe come from two sources. First, the LDLc at birth ranges between 50 and $70 \mathrm{mg} / \mathrm{dl}$ [69]. Second, in randomized clinical trials in which patients were treated with both a maximally tolerated statin and a PCSK9 inhibitor, the mean LDLc of the interventional group was $30 \mathrm{mg} / \mathrm{dl}$ [70] [71]. In this group, no adverse events were observed compared with the placebo group with a mean LDLc of $70 \mathrm{mg} / \mathrm{dl}$. Finally, it may not be necessary in an asymptomatic primary prevention group to obtain an LDLc much below $50 \mathrm{mg} / \mathrm{dl}$ to reverse atherosclerotic plaques [39]. Therefore, it seems prudent to choose an LDLc goal of $<50$ $\mathrm{mg} / \mathrm{dl}$ as a realistic, attainable goal that is clinically effective in stabilizing and 
reversing atherosclerotic plaques within 30 days [72].

The arguments for using one LDLc goal for all individuals at increased risks have previously been made [64]. Briefly, recommending one goal has the attributes of simplicity, safety, effectiveness, and achievability in almost all individuals. Furthermore, there are no convincing data that recommending high dose statins for high risk individuals and a moderate dose statin for intermediate risk individuals has any benefits. Rosuvastatin at $10 \mathrm{mg} /$ day is approximately equal in LDLc lowering capability to $40 \mathrm{mg} /$ day of atorvastatin [73]. In asymptomatic individuals at intermediate risk, rosuvastatin at $10 \mathrm{mg} / \mathrm{d}$ demonstrated a significant reduction in ASCVD [74]. Since rosuvastatin is $90 \%$ excreted unchanged, its interference with the metabolism of other concurrent medications is minimal. When combined with ezetimibe $10 \mathrm{mg}$, at least $60 \%$ reduction in circulating LDLc may be expected [75]. When that pharmaceutical combination is employed with a low cholesterol diet, almost all individuals will achieve a circulating LDLc below $50 \mathrm{mg} / \mathrm{dl}$ [64].

\section{2) Why utilize the CAC scan to diagnose ASCVD?}

There have been over 2000 articles describing the usefulness of the CAC scan to diagnose ASCVD. This test has been particularly useful for predicting future ASCVD events in various populations, including referral populations and multiethnic screening populations [76]. When compared to either treadmill-ECG or technetium-stress testing in patients evaluated for chest pain, CAC has a higher diagnostic ability for detection of obstructive angiographic CAD [77]. The great advantage of the CAC scan is its low cost ( $\$ 50$ to $\$ 150$ ), its non-invasiveness, its lack of adverse events (the radiation dose is less than $1 \mathrm{msev}-$ similar to living in Denver for 3 months), its simplicity (requires 10 minutes), and its broad applicability (can be performed by any modern CT scanner). Most importantly, a positive CAC scan is specific for the presence of atherosclerotic disease, not just the risk of disease [59]. It can be used to diagnose atherosclerotic disease in all adult age groups and has even been shown to be positive (albeit at a very low value) in obese adolescents [78]. The fact that it does not identify non-calcified plaques is only a minimal drawback as long as individuals with any CAC score are treated. We acknowledge that the decision to treat a CAC score between 1 and 10 is controversial because of the very low ten year ASCVD event rate in this range of CAC [52] [79]. However as recently reviewed, individuals with CAC scores between 1 and 10 have three times the ASCVD event rate as individuals with a zero score [53]. This information should be considered by the primary caregiver and discussed with the patient before treatment decisions are made.

There is currently an active debate as to whether the CAC scan can be used to exclude obstructive coronary artery disease [80]. There are both strong advocates and negators depending upon the patient selection, the definition of obstructive disease, and the "gold standard" that is used to confirm the diagnosis [81] [82] [83]. However, these studies are examining CAC testing in symptomatic patients either presenting to an emergency room or being referred to coronary angiography [84]. This population is not the focus of the current propos- 
al, which provides recommendations for asymptomatic individuals with varying numbers of ASCVD risk factors.

Scanning a general population with varying numbers of risk factors will result in different percentages of positive scores, depending upon their degree of risk. Insight into the percentage of positivity for different risk categories is available from the MESA clinical trial database in which 6814 healthy adults (free of cardiovascular disease) ages 45 to 84 yrs. were recruited from six diverse communities. In this large group that underwent calcium scanning close to enrollment, the percentage of calcium scan positive individuals were as follows: for very low ten year risk individuals ( $<5 \%$ ten year ASCVD risk), $21 \%$ were positive; for low risk individuals ( $5 \%$ to $7.5 \%$ ten year ASCVD risk), $43 \%$ were positive; for intermediate risk individuals ( $>7.5 \%$ to $20 \%$ ), $55 \%$ were positive; and for high risk individuals ( $>20 \%$ ten year ASCVD risk), $74 \%$ were positive [12]. Therefore, when screening a large population of healthy individuals, a significant number of persons will have identifiable cardiovascular disease, irrespective of their risk.

\section{3) Sensitivity and specificity of $C A C$}

Several authors have calculated the sensitivity and specificity of the CAC scan in different populations at various follow-up intervals [85] [86]. However, this calculation is dependent upon the end point that is chosen. For the approach to ASCVD prevention suggested in this article, the CAC endpoint is "to identify all individuals with a true positive CAC score." The reason for this endpoint is that these are the individuals who are recommended for therapy to reverse their atherosclerotic plaques. Individuals with a zero score will not be treated but rescanned in three to five years, the shortest interval for individuals with multiple major ASCVD risk factors [32] [87]. In this context, the sensitivity of CAC testing is extremely high (>95\%). The only false negatives will be individuals having a very low calcium score that was not identified because of calcification between radiographic cardiac slices or inherent differences between scanning equipment or techniques at different locations [88]. Similarly, specificity will also be close to $100 \%$ because false positive CAC scans are extremely rare [59]. Individuals with only non-calcified plaques will not be identified by this approach since they will have a zero calcium score. However, these individuals have very few non-calcified plaques and therefore they are at a very low risk for an ASCVD event and will qualify for rescanning in three to five years [53]. Compared with coronary angiography, CAC is superior for quantifying plaque burden and predicting future ASCVD events [89] [90].

\section{4) Feasibility}

Is this new approach to preventing ASCVD feasible? Recent studies suggest that it is [91]. Both rosuvastatin and ezetimibe are generic medications and have minimal side effects, specifically at the low dose of $10 \mathrm{mg} /$ day [92]. Since all modern CT scanners are able to perform CAC scans, CT scanning is available throughout the United States. As of 2017, there were approximately 43 CT scanners in the US per one million populations. Assuming that $50 \%$ of this pop- 
ulation would be over 40 and scan eligible, there would be 43 scanners per 500,000 individuals. By scanning this population over 5 years, there would be 43 scanners for every 100,000 population per year. Thus, each CT scanner would do 2325 scans per year or approximately 6 scans per day. A CAC scan takes $10 \mathrm{mi}$ nutes to complete, requires minimal preparation, and can be scheduled at the convenience of the CT facility and patient. If CAC scanning is introduced over a five year time frame, this resource will be available in almost all major communities. Even more attractive is the fact that introducing these new guidelines does not negate current guidelines. Gradual replacement will occur as more CAC scans are performed. Eventually, as ASCVD is reduced, not only will huge savings be realized, but many lives will be saved.

\section{5) Cost Assessment}

If one assumes that half of the populations are adults over the age of 40 years, then approximately 165 million individuals would be eligible for a CAC scan (excluding symptomatic individuals). If this program is introduced over five years, then at any given year, 33 million individuals would need to be scanned. Therefore 33 million $\times \$ 150 /$ scan is 5 billion dollars/year. If it is assumed that half of these scans are positive (Figure 2), then 17 million/yr. individuals need pharmacological treatment. The cost for these generic medications is 56 cents/day or 204 dollars/year/individual. Therefore, $\$ 204 \times 17$ million individuals equals 3.47 billion dollars/yr. Since these individuals would need treatment for their lifetime, the maximum number of individuals under therapy at five years would be 85 million. Since the U.S is spending 333 billion dollars/yr. on ASCVD (direct costs), the cost of this new program would be less than one twentieth of the current expenditures [1].

6) The suggested approach is similar to other accepted health maintenance guidelines.

For example, the American Cancer Society currently recommends colonoscopy to exclude colon cancer beginning at age 45 [93].

Colonoscopy detects the growth of polyps and early cancer which are harbingers of future invasive colon cancers [94]. It also recommends repeat testing at various intervals depending of the patient's degree of risk [95]. It is not a perfect test as some cancers may be overlooked. However, this approach has been shown to be cost effective and lifesaving [93]. The suggested approach in this article is similar in many respects to recommendations for colonoscopy except that colonoscopy is much more expensive, invasive, and uncomfortable for patients. Atherosclerotic disease is treated aggressively when identified with a positive coronary calcium scan. If negative, then a rescan in five years is warranted. Similar to colonoscopy in saving lives from cancer deaths, CAC scanning can save many more lives resulting from an atherosclerotic death [64].

\section{Challenges to a New Approach}

Change is difficult, particularly in the medical field, which includes both finan- 
cial and traditional institutions that do not necessarily benefit from alternative approaches to established diseases. Prevention and treatment of many diseases have continued long after the futility of traditional medical therapy has been demonstrated. For example, "blood-letting" to remove "bad humors" was continued for over 200 years and was even applied to Abraham Lincoln on his deathbed after being shot in the head in Ford's theatre [96]. Since 1955, more than 600,000 individuals have died every year from cardiovascular disease in spite of the availability new medications and procedures to protect the heart (Figure 1). These data by themselves should alert the medical community that a new approach is needed.

As with any new program, organizational issues will arise that present specific challenges. For example, caregivers will need to be trained in the assessment of both CAC scanning and aggressive medical therapy. Availability of computed tomography (CT) scanning in rural America will be challenging and appropriate transportation of patients to CT centers will need to be arranged. CT centers that currently do not provide CAC scanning will need to be convinced of the importance of this service. Finally, patient oriented health care organizations will need to embrace and support a new approach to ASCVD prevention. As difficult as these changes may be, they are not insurmountable. Many other major diseases in the past have presented similar challenges and positive solutions have been identified.

\section{Summary}

More than one half million heart attacks occur in the United States per year. Furthermore, the increasing costs of ASCVD medical care in the United States make the current approach to ASCVD unsustainable without negatively affecting other urgent medical needs. Current recommendations for preventing ASCVD have not been effective in reducing the epidemic in this country. The suggested new approach of aggressively identifying and treating asymptomatic patients with proven heart disease would correct many of the ineffective approaches in the past. Effective preventive therapy would save billions of dollars and millions of lives. The suggested approach could be readily integrated into the current healthcare system within five years.

\section{Conflicts of Interest}

The authors have no conflicts of interests relevant to this manuscript. The authors have nothing to disclose.

\section{References}

[1] AHA Editors (2017) Cardiovascular Disease: A Costly Burden for America, Projections through 2035 (2017).

https://healthmetrics.heart.org/cardiovascular-disease-a-costly-burden

[2] Stary, H.C., Chandler, A.B., Glagov, S., Guyton, J.R., Insull, W., Rosenfeld, M.E., et al. (1994) A Definition of Initial, Fatty Streak, and Intermediate Lesions of Atheros- 
clerosis. A Report from the Committee on Vascular Lesions of the Council on Arteriosclerosis, American Heart Association. Circulation, 89, 2462-2478. https://doi.org/10.1161/01.CIR.89.5.2462

[3] Libby, P. (2013) Mechanisms of Acute Coronary Syndromes and Their Implications for Therapy. The New England Journal of Medicine, 368, 2004-2013. https://doi.org/10.1056/NEJMra1216063

[4] Salek, L. and Marian, A.J. (1999) Genetic Basis of Coronary Atherosclerosis. Argentine Federation of Cardiology. $2^{\text {nd }}$ Virtual Congress of Cardiology.

http://scholar.google.com/scholar_url?url=https\%3A\%2F\%2Fwww.researchgate.net \%2Fprofile\%2FBiswajit_Majumder6\%2Fpost\%2Fgene_of_atherosclerosis\%2Fattach ment\%2F5a217e9c4cde266d58778524\%2FAS\%253A566789438672896\%2540151214 4540120\%2Fdownload\%2Fmariani.PDF\&hl=en\&sa=T\&oi=ggp\&ct=res\&cd=0\&d=1 2644560974358077224\&ei=sAY6XemNIc-aywTa3YjoCw\&scisig=AAGBfm29ssgnX O6CRNt5A7A9eSzgxSGgTg\&nossl=1\&ws=2259x1058\&at=Genetic\%20basis\%20of \%20coronary\%20atherosclerosis

[5] Youssef, G. and Budoff, M.J. (2012) Coronary Artery Calcium Scoring, What Is Answered and What Questions Remain. Cardiovascular Diagnosis and Therapy, 2, 94-105.

[6] Mokdad, A.H., Serdula, M.K., Dietz, W.H., et al. (1999) The Spread of the Obesity Epidemic in the United States, 1991-1998. JAMA, 282, 1519-1522.

https://doi.org/10.1001/jama.282.16.1519

[7] Fuster, V. (2009) The CVD Paradox: Mortality vs. Prevalence. Nature Reviews Cardiology, 6, 669. https://doi.org/10.1038/nrcardio.2009.187

[8] Benjamin, E.J., Virani, S.S., Callaway, C.W., Chamberlain, A.M., Chang, A.R., Cheng, S., et al. (2018) Heart Disease and Stroke Statistics-2018 Update. Circulation, 137, e67-e492.

[9] Morris, Z.S., Wooding, S. and Grant, J. (2011) The Answer Is 17 Years, What Is the Question: Understanding Time Lags in Translational Research. Journal of the Royal Society of Medicine, 104, 510-520. https://doi.org/10.1258/jrsm.2011.110180

[10] Wilkins, J.T., Ning, H., Berry, J., et al. (2012) Lifetime Risk and Years Lived Free of Total Cardiovascular Disease. JAMA, 308, 1795-1801.

https://doi.org/10.1001/jama.2012.14312

[11] Benner, J.S., Glynn, R.J., Mogun, H., et al. (2002) Long Term Persistence in Use of Statin Therapy in Elderly Patients. JAMA, 288, 455-461. https://doi.org/10.1001/jama.288.4.455

[12] Nasir, K., Bittencourt, M.S., Blaha, M.J., Blankstein, R., Agatson, A.S., Rivera, J.J., Miedema, M.D., Sibley, C.T., Shaw, L.J., Blumenthal, R.S., Budoff, M.J. and Krumholz, H.M. (2015) Implications of Coronary Artery Calcium Testing among Statin Candidates According to American College of Cardiology/American Heart Association Cholesterol Management Guidelines. Journal of the American College of Cardiology, 66, 1657-1668. https://doi.org/10.1016/j.jacc.2015.07.066

[13] Hutchins, R., Pignone, M.P., Sheridan, S.L. and Viera, A.J. (2015) Quantifying the Utility of Taking Pills for Preventing Adverse Health Outcomes: A Cross-Sectional Survey. Circulation: Cardiovascular Quality and Outcomes, 8, 155-163. https://doi.org/10.1161/CIRCOUTCOMES.114.001240

[14] Nicholls, S.J., Ballantyne, C.M., Barter, P.J., Chapman, J., Erbel, R.M., Libby, P., et al. (2011) Effect of Two Intensive Statin Regimens on Progression of Coronary Disease. The New England Journal of Medicine, 365, 2078-2087. https://doi.org/10.1056/NEJMoa1110874 
[15] Roberts, W.C. (1997) The Rule of 5 and the Rule of 7 in Lipid-Lowering by Statin Drugs. American Journal of Cardiology, 80, 106-107. https://doi.org/10.1016/S0002-9149(97)00298-1

[16] Welder, G., Zineh, I., Pacanowski, M.A., Troutt, J.S., Cao, G. and Konrad, R.J. (2010) High-Dose Atorvastatin Causes a Rapid Sustained Increase in Human Serum PCSK9 and Disrupts Its Correlation with LDLC Cholesterol. The Journal of Lipid Research, 51, 2714-2721. https://doi.org/10.1194/jlr.M008144

[17] Sudhop, T., Lütjohann, D., Kodal, A., Igel, M., Tribble, D.L., Shah, S., et al. (2002) Inhibition of Intestinal Cholesterol Absorption by Ezetimibe in Humans. Circulation, 106, 1943-1948. https://doi.org/10.1161/01.CIR.0000034044.95911.DC

[18] Stein, E., Stender, S., Mata, P., Sager, P., Ponsonnet, D., Melani, L., et al. (2004) Achieving Lipoprotein Goals in Patients at High Risk with Severe Hypercholesterolemia: Efficacy and Safety of Ezetimibe Co-Administered with Atorvastatin. American Heart Journal, 148, 447-455. https://doi.org/10.1016/j.ahj.2004.03.052

[19] Cholesterol Treatment Trialists' (CTT) Collaborators (2012) The Effects of Lowering LDLC Cholesterol with Statin Therapy in People at Low Risk of Vascular Disease: Meta-Analysis of Individual Data from 27 Randomized Trials. The Lancet, 380, 581-590. https://doi.org/10.1016/S0140-6736(12)60367-5

[20] Cholesterol Treatment Trialists' (CTT) Collaboration (2010) Efficacy and Safety of More Intensive Lowering of LDLC Cholesterol: A Meta-Analysis of Data from 170,000 Participants in 26 Randomized Trials. The Lancet, 376, 1670-1681. https://doi.org/10.1016/S0140-6736(10)61350-5

[21] Sheffield, K.M., Stone, P.S., Benarroch-Gampel, J., Goodwin, J.S., Boyd, C.A., Zhang, D., et al. (2013) Overuse of Preoperative Cardiac Stress Testing in Medicare Patients Undergoing Elective Non-Cardiac Surgery. Annals of Surgery, 257, 73-80. https://doi.org/10.1097/SLA.0b013e31826bc2f4

[22] Topol, E.J. and Nissen, S.E. (1995) Our Preoccupation with Coronary Luminology: The Dissociation between Clinical and Angiographic Findings in Ischemic Heart Disease. Circulation, 92, 2333-2342. https://doi.org/10.1161/01.CIR.92.8.2333

[23] Little, W.C., Constantinescu, M., Applegate, R.J., Kutcher, M.A., Burrows, M.T., Kahl, F.R. and Santamore, W.P. (1988) Can Coronary Angiography Predict the Site of a Subsequent Myocardial Infarction in Patients with Mild-to-Moderate Coronary Artery Disease? Circulation, 78, 1157-1166. https://doi.org/10.1161/01.CIR.78.5.1157

[24] Boden, W.E., O’Rourke, R.A., Teo, K.T., Hartigan, P.M., Maron, D.J., Kostuk, W.J., et al. (2007) Optimal Medical Therapy with or without PCI for Stable Coronary Disease. The New England Journal of Medicine, 356, 1503-1516. https://doi.org/10.1056/NEJMoa070829

[25] Mahmarian, J.J., Dakik, H.A., Filipchuk, N.G., Shaw, L.J., Iskander, S.S., Ruddy, T.D., et al. (2006) An Initial Strategy of Intensive Medical Therapy Is Comparable to That of Coronary Revascularization for Suppression of Scintigraphic Ischemia in High Risk But Stable Survivors of Acute Myocardial Infarction. Journal of the American College of Cardiology, 48, 2458-2467. https://doi.org/10.1016/j.jacc.2006.07.068

[26] Khanji, M.Y., Bicalho, V.S., van Waardhuizen, C.N., et al. (2016) Cardiovascular Risk Assessment: A Systematic Review of Guidelines. Annals of Internal Medicine, 165, 713-722. https://doi.org/10.7326/M16-1110

[27] Grundy, S.M., Stone, N.J., Bailey, A.L., et al. (2018) AHA/ACC/AACVPR/AAPA /ABC/ACPM/ADA/AGS/APhA/ASPC/NLA/PCNA Guideline on the Management of Blood Cholesterol: A Report of the American College of Cardiology/American 
Heart Association Task Force on Clinical Practice Guidelines. Circulation, 139, e1082-e1143. https://doi.org/10.1161/CIR.0000000000000625

[28] Cabana, M.D., Rand, C.S., Powe, N.R., Wu, A.W., Wilson, M.H., Abboud, P.-A.C., et al. (1999) Why Don't Physicians Follow Clinical Practice Guideline? A Framework for Improvement. JAMA, 282, 1458-1465.

https://doi.org/10.1001/jama.282.15.1458

[29] Schade, D.S. and Eaton, R.P. (2018) The Basis of Atherosclerotic Guidelines-Time for a Change? World Journal of Cardiovascular Diseases, 8, 337-352. https://doi.org/10.4236/wjcd.2018.87033

[30] Fanaroff, A.C., Califf, R.M., Windecker, S., Smith Jr., S.C. and Lopes, R.D. (2019) Levels of Evidence Supporting American College of Cardiology/American Heart Association and European Society of Cardiology, 2008-2018. JAMA, 321, 1069-1080. https://doi.org/10.1001/jama.2019.1122

[31] Alenghat, F.J. and Davis, A.M. (2019) Management of Blood Cholesterol. JAMA, 321, 800-801. https://doi.org/10.1001/jama.2019.0015

[32] Greenland, P., Smith, S.C. and Grundy, S.M. (2001) Improving Coronary Heart Disease Risk Assessment in Asymptomatic People. Circulation, 104, 1863-1867. https://doi.org/10.1161/hc4201.097189

[33] Ford, E.S., Giles, W.H. and Mokdad, A.H. (2004) The Distribution of 10-Year Risk for Coronary Heart Disease among U.S Adults. Journal of the American College of Cardiology, 43, 1791-1796. https://doi.org/10.1016/j.jacc.2003.11.061

[34] Thanassoulis, G., Sniderman, A.D. and Pencina, M.J. (2018) A Long-Term Benefit Approach vs. Standard Risk-Based Approaches for Statin Eligibility in Primary Prevention. JAMA Cardiology, 3, 1090-1095. https://doi.org/10.1001/jamacardio.2018.3476

[35] Silverman, M.G., Blaha, M.J., Krumholz, H.M., et al. (2014) Impact of Coronary Artery Calcium on Coronary Heart Disease Events in Individuals at the Extremes of Traditional Risk Factor Burden: The Multi-Ethnic Study of Atherosclerosis. European Heart Journal, 35, 2232-2241. https://doi.org/10.1093/eurheartj/eht508

[36] Greenland, P., LaBree, L., Azen, S.P., Doherty, T.M. and Detrano, R.C. (2004) Coronary Artery Calcium Score Combined with Framingham Score for Risk Prediction in Asymptomatic Individuals. JAMA, 291, 210-215.

https://doi.org/10.1001/jama.291.2.210

[37] Roberts, E.T., Horne, A., Martin, S.S., Blaha, M.J., Blankstein, R., Budoff, M.J., et al. (2015) Cost-Effectiveness of Coronary Artery Calcium Testing for Coronary Heart and Cardiovascular Disease Risk Prediction to Guide Statin Allocation: The Multi-Ethnic Study of Atherosclerosis (MESA). PLoS ONE, 10, e0116377. https://doi.org/10.1371/journal.pone.0116377

[38] Mamudu, H.M., Paul, T.K., Veeranki, S.P. and Budoff, M. (2014) The Effects of Coronary Artery Calcium Screening on Behavioral Modification, Risk Perception, and Medication Adherence among Asymptomatic Adults: A Systematic Review. Atherosclerosis, 236, 338-350. https://doi.org/10.1016/j.atherosclerosis.2014.07.022

[39] Gao, W.Q., Feng, Q.Z., Li, Y.F., Li, Y.X., Huang, Y., Chen, Y.M., et al. (2014) Systematic Study of the Effects of Lowering Low-Density Lipoprotein-Cholesterol on Regression of Coronary Atherosclerotic Plaques Using Intravascular Ultrasound. BMC Cardiovascular Disorders, 14, 60-78. https://doi.org/10.1186/1471-2261-14-60

[40] Radford, N.B., Defina, L.F., Leonard, D., Barlow, C.E., Willis, B.L., Gibbons, L.W., et al. (2018) Cardiorespiratory Fitness, Coronary Artery Calcium, and Cardiovascular Disease Events in a Cohort of Generally Healthy Middle Age Men. Circulation, 
137, 1888-1895. https://doi.org/10.1161/CIRCULATIONAHA.117.032708

[41] Zhong, V.W., Van Horn, L., Cornelis, M.C., Wilkins, J.T., Ning, H., Carnethon, M.R., et al. (2019) Associations of Dietary Cholesterol or Egg Consumption with Incident Cardiovascular Disease and Mortality. JAMA, 321, 1081-1095. https://doi.org/10.1001/jama.2019.1572

[42] Eckel, R.H. (2019) Reconsidering the Importance of the Association of Egg Consumption and Dietary Cholesterol with Cardiovascular Disease Risk. JAMA, 321, 1055-1056. https://doi.org/10.1001/jama.2019.1850

[43] McClelland, R.L., Jorgensen, N.W., Budoff, M., Blaha, M.J., Post, W.S., Kronmal, R.A., et al. (2015) 10-Year Coronary Heart Disease Risk Prediction Using Coronary Artery Calcium and Traditional Risk Factors Derivation in the MESA (Multi-Ethnic Study of Atherosclerosis) with Validation in the HNR (Heinz Nixdorf Recall) Study and the DHS (Dallas Heart Study). Journal of the American College of Cardiology, 66, 1643-1653. https://doi.org/10.1016/j.jacc.2015.08.035

[44] Hecht, H., Blaha, M.J., Berman, D.S., Nasir, K., Budoff, M., Leipsic, J., et al. (2017) Clinical Indications for Coronary Artery Calcium Scoring in Asymptomatic Patients: Expert Consensus Statement from the Society of Cardiovascular Computed Tomography. Journal of Cardiovascular Computed Tomography, 11, 157-168. https://doi.org/10.1016/j.jcct.2017.02.010

[45] Rumberger, J.A., Schwartz, R.S., Simons, B., Sheedy, P.F., Edwards, W.D. and Fitzpatrick, L.A. (1994) Relation of Coronary Calcium Determined by Electron Beam Computed Tomography and Lumen Narrowing Determined by Autopsy. American Journal of Cardiology, 74, 1169-1173. https://doi.org/10.1016/0002-9149(94)90176-7

[46] Tota-Maharaj, R., Blaha, M.J., McEvoy, J.W., Blumenthal, R.S., Muse, E.D., Budoff, M.J., et al. (2012) Coronary Artery Calcium for the Prediction of Mortality in Young Adults $<45$ Years Old and Elderly Adults $>75$ Years Old. European Heart Journal, 33, 2955-2962. https://doi.org/10.1093/eurheartj/ehs230

[47] Baumgart, D., Schmermund, A., George, G., Haude, M., Ge, J., Adamzik, M., et al. (1997) Comparison of Electron Beam Computed Tomography with Intracoronary Ultrasound and Coronary Angiography for Detection of Coronary Atherosclerosis. Journal of the American College of Cardiology, 30, 57-64. https://doi.org/10.1016/S0735-1097(97)00147-2

[48] Cheng, V.Y., Lepor, N.E., Madyoon, H., et al. (2007) Presence and Severity of Noncalcified Coronary Plaque on 64-Slice Computed Tomographic Coronary Angiography in Patients with Zero and Low Coronary Artery Calcium. American Journal of Cardiology, 99, 1183-1186. https://doi.org/10.1016/j.amjcard.2006.12.026

[49] Greenland, P. (2015) When Nothing Is Really Something New Evidence of the Importance of Zero Coronary Calcium. Journal of the American College of Cardiology: Cardiovascular Imaging, 8, 910-912. https://doi.org/10.1016/j.jcmg.2015.02.028

[50] Anand, D.V., Lim, E., Hopkins, D., Corder, R., Shaw, L.J., Sharp, P., et al. (2006) Risk Stratification in Uncomplicated Type 2 Diabetes: Prospective Evaluation of the Combined Use of Coronary Artery Calcium Imaging and Selective Myocardial Perfusion Scintigraphy. European Heart Journal, 27, 713-721. https://doi.org/10.1093/eurheartj/ehi808

[51] Kramer, C.K., Zinman, B., Gross, J.L., Canani, L.H., Rodrigues, T.C., Azevedo, M.J., et al. (2013) Coronary Artery Calcium Score Prediction of All Cause Mortality and Cardiovascular Events in People with Type 2 Diabetes: Systematic Review and Meta-Analysis. BMJ, 346, f1654. https://doi.org/10.1136/bmj.f1654 
[52] Sarwar, A., Shaw, L.J., Shapiro, M.D., Blankstein, R., Hoffman, U., Cury, R.C., et al. (2009) Diagnostic and Prognostic Value of Absence of Coronary Artery Calcification. Journal of the American College of Cardiology: Cardiovascular Imaging, 2, 675-688. https://doi.org/10.1016/j.jcmg.2008.12.031

[53] Budoff, M.J., McClelland, R.L., Nasir, K., Greenland, P., Kronmal, R.A., Kondos, G.T., Shea, S., Lima, J.A. and Blumenthal, R.S. (2009) Cardiovascular Events with Absent or Minimal Coronary Calcification: The Multi-Ethnic Study of Atherosclerosis (MESA). American Heart Journal, 158, 554-561.

https://doi.org/10.1016/j.ahj.2009.08.007

[54] Budoff, M.J., Lane, K.L., Bakhsheshi, H., Mao, S., Grassman, B.O., Friedman, B.C. and Brundage, B.H. (2000) Rates of Progression of Coronary Calcium by Electron Beam Tomography. American Journal of Cardiology, 86, 8-11. https://doi.org/10.1016/S0002-9149(00)00820-1

[55] Achenbach, S., Ropers, D., Mohlenkamp, S., Schmermund, A., Muschiol, G., Groth, J., et al. (2001) Variability of Repeated Coronary Artery Calcium Measurements by Electron Beam Tomography. American Journal of Cardiology, 87, 210-213. https://doi.org/10.1016/S0002-9149(00)01319-9

[56] US Preventive Services Task Force (2018) Risk Assessment for Cardiovascular Disease with Nontraditional Risk Factors. JAMA, 320, 272-280. https://doi.org/10.1001/jama.2018.8359

[57] Nasir, K. and Clouse, M. (2012) Role of Nonenhanced Multidetector CT Coronary Artery Calcium Testing in Asymptomatic and Symptomatic Individuals. Radiology, 264, 637-649. https://doi.org/10.1148/radiol.12110810

[58] Greenland, P., Blaha, M., Budoff, M., et al. (2018) Coronary Calcium Score and Cardiovascular Risk. Journal of the American College of Cardiology, 72, 434-447. https://doi.org/10.1016/j.jacc.2018.05.027

[59] Hecht, H.S. (2015) Coronary Artery Calcium Scanning: Past, Present, and Future. Journal of the American College of Cardiology Cardiovascular Imaging, 8, 579-596. https://doi.org/10.1016/j.jcmg.2015.02.006

[60] Min, J.K., Lin, F.Y., Gidseg, D.S., et al. (2010) Determinants of Coronary Calcium Conversion among Patients with a Normal Coronary Calcium Scan. Journal of the American College of Cardiology, 55, 1110-1117. https://doi.org/10.1016/j.jacc.2009.08.088

[61] Gagne, C., Bays, H.E., Weiss, S.R., Mata, P., Quinto, K., Melino, M., et al. (2002) Efficacy and Safety of Ezetimibe Added to Ongoing Statin Therapy for Treatment of Patients with Primary Hypercholesterolemia. American Journal of Cardiology, 90, 1084-1091. https://doi.org/10.1016/S0002-9149(02)02774-1

[62] Health Warehouse Editors. HealthWarehouse.com. https://www.healthwarehouse.com/rosuvastatin-10mg-tablets-20551.html

[63] Eaton, R.P., Burge, M.R., Comerci, G., Cavanaugh, B., Ramo, B. and Schade, D.S. (2016) Abnormal Coronary Artery Calcium Scans in Asymptomatic Patients. The American Journal of Medicine, 130, 394-397. https://doi.org/10.1016/j.amjmed.2016.10.006

[64] Schade, D.S., Obenshain, S.S., Ramo, B. and Eaton, R.P. (2019) A Feasible, Simple, Cost-Saving Program to End Cardiovascular Disease in the United States. The American Journal of Medicine. https://doi.org/10.1016/j.amjmed.2019.03.043

[65] Schade, D.S., Cavanaugh, B., Ramo, B. and Eaton, R.P. (2016) The Application of the LDLC Principle. World Journal of Cardiovascular Diseases, 6, 109-125. https://doi.org/10.4236/wjcd.2016.65012 
[66] Carr, B.R., Parker, C.R., Milewich, L., Porter, J.C., MacDonald, P.C. and Simpson, E.R. (1980) The Role of Low Density, High Density, and Very Low Density Lipoproteins in Steroidogenesis by the Human Fetal Adrenal Gland. Endocrinology, 106, 1854-1860. https://doi.org/10.1210/endo-106-6-1854

[67] Rainey, W.E., Rehman, K.S. and Carr, B.R. (2004) The Human Fetal Adrenal: Making Adrenal Androgens for Placental Estrogens. Seminars in Reproductive Medicine, 22, 327-336. https://doi.org/10.1055/s-2004-861549

[68] Schonfeld, G. (2003) Familial Hypobetalipoproteinemia: A Review. The Journal of Lipid Research, 44, 878-883. https://doi.org/10.1194/jlr.R300002-JLR200

[69] O’Keefe, J.H., Cordain, L., Harris, W.H., Moe, R.M. and Vogel, R. (2004) Optimal Low-Density Lipoprotein Is 50 to $70 \mathrm{mg} / \mathrm{dl}$ : Lower Is Better and Physiologically Normal. Journal of the American College of Cardiology, 43, 2142-2146. https://doi.org/10.1016/j.jacc.2004.03.046

[70] Sabatine, M.S., Giugliano, R.P., Keech, A.C., Honarpour, N., Wiviott, S.D., Murphy, S.A., et al. and the FOURIER Steering Committee and Investigators (2017) Evolocumab and Clinical Outcomes in Patients with Cardiovascular Disease. The New England Journal of Medicine, 376, 1713-1722. https://doi.org/10.1056/NEJMoa1615664

[71] Sabatine, M.S., Wiviott, S.D., Im, K., Murphy, S.A. and Giugliano, R.P. (2018) Efficacy and Safety of Further Lowering of Low-Density Lipoprotein Cholesterol in $\mathrm{Pa}$ tients Starting with Very Low Levels: A Meta-Analysis. JAMA Cardiology, 3, 823-828. https://doi.org/10.1001/jamacardio.2018.2258

[72] Nakamura, T., Obata, J.E., Kitta, Y., Takano, H., Kobayashi, T., Fujioka, D., Saito, Y., Kodama, Y., Kawabata, K., Mende, A., Yano, T., Hirano, M., Sano, K., Nakamura, K., Kugiyama, K., et al. (2008) Rapid Stabilization of Vulnerable Carotid Plaque within 1 Month of Pitavastatin Treatment in Patients with Acute Coronary Syndrome. Journal of Cardiovascular Pharmacology, 51, 365-371. https://doi.org/10.1097/FJC.0b013e318165dcad

[73] Brewer, H.B. (2003) Benefit-Risk Assessment of Rosuvastatin 10 to 40 Milligrams. American Journal of Cardiology, 92, 23K-29K. https://doi.org/10.1016/S0002-9149(03)00779-3

[74] Yusuf, S., Bosch, J., Dagenais, G., Zhu, J., Xavier, D., Liu, L., et al. (2016) Cholesterol Lowering in Intermediate-Risk Persons without Cardiovascular Disease. The New England Journal of Medicine, 374, 2021-2031. https://doi.org/10.1056/NEJMoa1600176

[75] Mikhailidis, D.P., Wierzbicki, A.S., Daskalopoulou, S.S., Al-Saady, N., Griffiths, H., Hamilton, G., et al. (2005) The Use of Ezetimibe in Achieving Low Density Lipoprotein Lowering Goals in Clinical Practice: Position Statement of a United Kingdom Consensus Panel. Current Medical Research and Opinion, 21, 959-969. https://doi.org/10.1185/030079905X48447

[76] Bild, D.E., Bluemke, D.A., Burke, G.L., Detrano, R., Diez Roux, A.V., Folsom, A.R., et al. (2005) Ethnic Differences in Coronary Calcification the Multi-Ethnic Study of Atherosclerosis (MESA). Circulation, 111, 1313-1320. https://doi.org/10.1093/aje/kwf113

[77] Shavelle, D.M., Budoff, M.J., LaMont, D.H., Shavelle, R.M., Kennedy, J.M. and Brundage, B.H. (2000) Exercise Testing and Electron Beam Computed Tomography in the Evaluation of Coronary Artery Disease. Journal of the American College of Cardiology, 36, 32-38. https://doi.org/10.1016/S0735-1097(00)00696-3

[78] Bacha, F., Edmundowicz, D., Sutton-Tyrell, K., Lee, S., Fjayli, H. and Arslanian, S.A. (2014) Coronary Artery Calcification in Obese Youth: What Are the Phenotypic 
and Metabolic Determinants? Diabetes Care, 37, 2632-2639. https://doi.org/10.2337/dc14-0193

[79] Budoff, M.J., Shaw, L.J., Liu, S.T., Weinstein, S.R., Mosler, T.P., Tseng, P.H., et al. (2007) Long-Term Prognosis Associated with Coronary Calcification. Journal of the American College of Cardiology, 49, 1860-1870. https://doi.org/10.1016/j.jacc.2006.10.079

[80] Gottlieb, I., Miller, J.M., Arbab-Zadeh, A., Dewey, M., Clouse, M.E., Sra, L., et al. (2010) The Absence of Coronary Calcification Does Not Exclude Obstructive Coronary Artery Disease or Need for Revascularization in Patients Referred for Conventional Coronary Angiography. Journal of the American College of Cardiology, 55, 627-634. https://doi.org/10.1016/j.jacc.2009.07.072

[81] Rubinshtein, R., Gaspar, T., Halon, D.A., Goldstein, J., Peled, N. and Lewis, B.S. (2007) Prevalence and Extent of Obstructive Coronary Artery Disease in Patients with Zero or Low Calcium Score Undergoing 64-Slice Cardiac Multidetector Computed Tomography for Evaluation of a Chest Pain Syndrome. American Journal of Cardiology, 99, 472-475. https://doi.org/10.1016/j.amjcard.2006.08.060

[82] Henneman, M.M., Schuijf, J.D., Pundziute, G., van Werkhoven, J.M., van der Wall, E.E., Jukeme, W., et al. (2008) Noninvasive Evaluation with Multislice Computed Tomography in Suspected Acute Coronary Syndrome: Plaque Morphology on Multislice Computed Tomography versus Coronary Calcium Score. Journal of the American College of Cardiology, 52, 216-222. https://doi.org/10.1016/j.jacc.2008.04.012

[83] Knez, A., Becker, A., Leber, A., White, C., Becker, C.R., Reiser, M.F., et al. (2004) Relation of Coronary Calcium Scores by Electron Beam Tomography to Obstructive Disease in 2,115 Symptomatic Patients. American Journal of Cardiology, 93, 1150-1152. https://doi.org/10.1016/j.amjcard.2004.01.044

[84] Villines, T.C., Hulten, E.A., Shaw, L.J., Goyal, M., Dunning, A., Achenbach, S., et al. (2011) Prevalence and Severity of Coronary Artery Disease and Adverse Events among Symptomatic Patients with Coronary Artery Calcification Scores of Zero Undergoing Coronary Computed Tomography Angiography. Journal of the American College of Cardiology, 58, 2533-2540. https://doi.org/10.1016/j.jacc.2011.10.851

[85] Cleary, P.A., Orchard, T.J., Genuth, S., Wong, N.D., Detrano, R., Backlund, J.Y.C., Zinman, B., Jacobson, A., Sun, W., Lachin, J.M., Nathan, D.M. for the DCCT/EDIC Research Group (2006) The Effect of Intensive Glycemic Treatment on Coronary Artery Calcification in Type Diabetic Participants of the Diabetes Control and Complications Trial/Epidemiology of Diabetes Intervention and Complications (DCCT/EDIC) Study. Diabetes, 55, 3556-3565. https://doi.org/10.2337/db06-0653

[86] Hanifehpour, Y., Motevalli, M., Ghanaati, H., Shahriari, M. and Ghasabeh, M.A. (2016) Diagnostic Accuracy of Coronary Calcium Score Less than 100 in Excluding Coronary Artery Disease. Iranian Journal of Radiology, 13, e16705. https://doi.org/10.5812/iranjradiol.16705

[87] Greenland, P., Knoll, M.D., Stamler, J., et al. (2003) Major Risk Factors as Antecedents of Fatal and Nonfatal Coronary Heart Disease Events. JAMA, 290, 891-897. https://doi.org/10.1001/jama.290.7.891

[88] Baratloo, A., Hosseini, M., Negida, A. and Ashal, G.E. (2015) Part 1: Simple Definition and Calculation of Accuracy, Sensitivity and Specificity. Emergency, 3, 48-49.

[89] Keelan, P.C., Bielak, L.F., Ashai, K., Jamjoum, L.S., Denktas, A.E., Rumberger, J.A., Sheedy, II P.F., Peyser, P.A. and Schwartz, R.S. (2001) Long-Term Prognostic Value of Coronary Calcification Detected by Electron-Beam Computed Tomography in 
Patients Undergoing Coronary Angiography. Circulation, 104, 412-417. https://doi.org/10.1161/hc2901.093112

[90] Rumberger, J.A., Simons, D.B., Fitzpatrick, L.A., Sheedy, P.F. and Schwartz, R.S. (1995) Coronary Artery Calcium Area by Electron Beam Computed Tomography and Coronary Atherosclerotic Plaque Area. A Histopathologic Correlative Study. Circulation, 92, 2157-2162. https://doi.org/10.1161/01.CIR.92.8.2157

[91] Lazar, L.D., Pletcher, M.J., Coxson, P.G., Bibbins-Domingo, K. and Goldman, L. (2011) Cost-Effectiveness of Statin Therapy for Primary Prevention in a Low-Cost Statin Era. Circulation, 124, 146-153. https://doi.org/10.1161/CIRCULATIONAHA.110.986349

[92] Mirzaee, S., Thein, P.M., Nogic, J., Nerlekar, N., Nasis, A. and Brown, A.J. (2018) The Effect of Combined Ezetimibe and Statin Therapy versus Statin Therapy Alone on Coronary Plaque Volume Assessed by Intravascular Ultrasound: A Systematic Review and Meta-Analysis. Journal of Clinical Lipidology, 12, 1133-1140. https://doi.org/10.1016/j.jacl.2018.06.001

[93] Wolf, A., Fontham, E.T.H., Church, T.R., Flowers, C.R., Guerra, C.E., LaMonte, S.J., et al. (2018) Colorectal Cancer Screening for Average-Risk Adults: 2018 Guideline Update from the American Cancer Society. CA: A Cancer Journal for Clinicians, 68, 250-281. https://doi.org/10.3322/caac.21457

[94] Imperiale, T.F., Wagner, D.R., Lin, C.Y., Larkin, G.N., Rogge, J.D., Ransohoff, D.F., et al. (2002) Results of Screening Colonoscopy among Persons 40 to 49 Years of Age. The New England Journal of Medicine, 346, 1781-1785. https://doi.org/10.1056/NEJM200206063462304

[95] Lieberman, D.A., Weiss, D.G., Harford, W.V., Ahnen, D.J., Provenzale, D., Sontag, S.J., et al. (2007) Five-Year Colon Surveillance after Screening Colonoscopy. Gastroenterology, 133, 1077-1085. https://doi.org/10.1053/j.gastro.2007.07.006

[96] Lattimer, J.K. (1964) The Wound That Killed Lincoln. JAMA, 187, 480-489. https://doi.org/10.1001/jama.1964.03060200012002

\section{Abbreviation List}

1) $\mathrm{ASCVD}=$ atherosclerotic cardiovascular disease

2) $\mathrm{LDLc}=$ low density lipoprotein cholesterol

3) $\mathrm{AHA}=$ American Heart Association

4) $\operatorname{PCSK} 9=$ proprotein convertase subtilsin-kexin type 9

5) $\mathrm{CAC}=$ coronary artery calcium

6) $\mathrm{MESA}=$ multi-ethnic study of atherosclerosis

7) $\mathrm{CT}=$ computed tomography 